\title{
How COVID-19 is impacting and reshaping the airline industry
}

\author{
Laurie Garrow $^{1} \cdot$ Virginie Lurkin ${ }^{2}$
}

Received: 12 November 2020 / Accepted: 13 November 2020 / Published online: 8 January 2021

(c) The Author(s), under exclusive licence to Springer Nature Limited part of Springer Nature 2021

\begin{abstract}
The Airline Group of the International Federation of Operations Research (AGIFORS) held a conference in October 2020 that included keynote addresses from KLM Royal Dutch Airlines and Airbus, as well as three panels that included representatives from 11 airlines throughout the world that focused on how COVID-19 is impacting and reshaping the airline industry. This paper presents key themes that emerged from these discussions, including the impact of border closures on airline operations and demand forecasts; the shift in development priorities within revenue management departments; and outlooks for how passenger preferences, booking curves, and fare product restrictions may change after the COVID-19 pandemic.
\end{abstract}

Keywords COVID-19 $\cdot$ Demand forecasting $\cdot$ Schedule planning $\cdot$ Travel restrictions

\section{Introduction}

The Airline Group of the International Federation of Operations Research (AGIFORS) is a nonprofit organization dedicated to the advancement of operations research within aviation. From October 20 to 23, 2020, AGIFORS held its 60th Annual Symposium on a virtual platform. As part of the program, two keynote presentations were given by Sander Stomph, a Vice President at KLM Royal Dutch Airlines and Robert Lange, a Senior Vice President at Airbus. In addition, three panels were held that focused on how COVID19-related impacts are affecting and reshaping airline operations, crew management, and revenue management. The panels included representatives from Airbus, Boeing, the Massachusetts Institute of Technology (MIT), and 11 airlines from across the world: AeroMéxico, Air Canada, Air France-KLM, American, Cathay Pacific, Copa, Emirates, IndiGo, United, Qatar, and SAS.

Laurie Garrow

laurie.garrow@ce.gatech.edu

Virginie Lurkin

v.j.c.lurkin@tue.nl

1 School of Civil and Environmental Engineering, Georgia Institute of Technology, 790 Atlantic Drive, Atlanta, GA 30322-0355, USA

2 Department of Industrial Engineering \& Innovation Sciences, Operations Planning Accounting \& Control, Eindhoven University of Technology, Atlas 4.402, P.O. Box 513, 5600 MB Eindhoven, The Netherlands
This paper presents key themes that emerged from these discussions, including the impact of border closures on airline operations and demand forecasts; outlooks for how passenger mix, booking curves, and fare product restrictions that have changed during COVID-19; and shifts that are occurring in development priorities within revenue management (RM) departments. These and other themes are discussed below.

\section{Current state of the airline industry}

Historically, the commercial aviation industry has supported more than 80 million jobs worldwide and has contributed up to $8 \%$ of the gross domestic product. More than $30 \%$ of all international trade by value is carried by air and approximately $60 \%$ of international tourists travel by air (Lange 2020). However, as noted by Lange (2020) at Airbus:

In 2020, we've seen everything fall off a cliff. At the worst point in April, two thirds of the world's fleet of aircraft was grounded, $90 \%$ of operations were not happening and even more so for international operations, where it was more like $98 \%$. And we have the latest IATA [International Air Transport Association] estimation of where we will end up at the end of the year, which is around $60 \%$ down or $65 \%$ down on last year. 
Never before has the airline industry seen such a dramatic and sustained decline in air passenger demand. Previous crises like SARS ${ }^{1}$ in 2003 or the 9/11 terrorist attacks in 2001 have been more limited geographically or more limited in time and duration (Lange 2020). Therefore, it becomes more challenging to model exactly when airlines will be able to restart operations and when flight operations and customer demand will return to pre-COVID-19 levels. Current projections of when worldwide traffic will return to 2019 levels are between 2023 and 2025 (Lange 2020).

The dramatic decrease in demand, combined with this expected multi-year recovery period, is causing many challenges for the airline industry, the first of which is "to survive and get some revenue in when there is [practically] no demand" (Westerhof 2020). Lange (2020) emphasized that while the current focus is on survival, how airlines handle the recovery period is equally critical:

Our whole industry finds itself in an unprecedented situation where this avoidance of loss or minimizing of loss is driving all of our thinking and decisionmaking...And, ironically, most major airlines in the world are currently in a situation where they have more months of cash flow coverage in terms of their cash burn than they do in normal operations-which should be a warning sign to all of us because that is saying that by not operating, airlines are continuing to survive. But that once airlines start operating again, according to the way that restart is managed, their risk exposure to cash burn increases. So, we see a situation where everybody is being extremely cautious.

\section{Recovery and the impact of travel restrictions}

The airline industry has been seeing a slow and sustained recovery since passenger demands hit a low point in the spring of 2020 (Aznavurian 2020), with recovery occurring more quickly in domestic markets. As a result, some airlines that have a strong domestic presence (such as some in China) are experiencing faster recoveries than airlines such as AeroMéxico and Copa that relied heavily pre-COVID-19 on international markets (Aznavurian 2020; Dominguez 2020; Lange 2020). To help generate additional revenue, AeroMéxico is opening new city pairs domestically while restrictions for international flights are in place. Copa Airlines, in the Central American country of Panama, was shut down for seven months (i.e., March 17 to October 12), and has

\footnotetext{
${ }_{1}^{1}$ Severe acute respiratory syndrome-related coronavirus, or SARS$\mathrm{CoV}$.
}

just reactivated 30 aircraft to fly in the fourth quarter (Q4) of 2020 but is not expecting to put more than 45-50 aircraft into service in Q1 2021; before COVID-19, Copa had a fleet of about 100 aircraft (Dominguez 2020). Several airlines have also increased cargo flight operations (Garrow 2020).

The goal of starting service in new domestic markets and initiating new cargo routes and/or increasing cargo flights is to help generate additional revenues, particularly given the numerous and ever-evolving travel restrictions that are in place across the world. As Reynolds (2020) of Emirates observed, "every country seems to be changing government regulations on a daily basis. First you have a 14-day quarantine, then it lifts, but now certain destinations require $\mathrm{PCR}^{2}$ tests within $72 \mathrm{~h}$ of arrival or certificates you are COVID free, and certain countries will not allow entry of travelers from particular destinations."

Multiple panelists underscored the impact of travel restrictions on demand. Pablo Aznavurian of AeroMéxico noted that "nowadays, a high percentage of the market is derived from strategic alliances-either through mega-alliances like SkyTeam ${ }^{\circledR}$, oneworld ${ }^{\circledR}$, or Star Alliance $\AA$; code shares; or joint ventures. The closure of borders... around the globe has restricted the ability to exploit the benefits of alliances." Robert Lange at Airbus and Jason Herter at IndiGo stressed that these travel restrictions are a primary reason for people not traveling and are leading to pent-up demand. As Lange (2020) explained:

The repetitive passenger surveys that airlines and travel institutions undertake now start to show that the main reason for people not traveling is not the health risk in terms of the fear of becoming ill-but it's the worry and inconvenience of being stuck somewhere you don't want to be.

Herter (2020) observed that at IndiGo, they have seen "a lot of pent-up demand just waiting to fly" and that some flights are selling out within just a day or two when markets open up and travel restrictions are lifted.

Given the influence that travel restrictions have on demand, combined with the predominance of local and national policies, which themselves are unstable and changing very rapidly, there remains a research need to determine a correlation between the propagation of health measures being taken in countries and the restrictions on the restart of airline operations (Lange 2020). Several airlines and professional organizations, such as the International Air Transport Association, have been conducting studies on the effectiveness of different travel restrictions related to testing and quarantines. Air Canada

\footnotetext{
2 Polymerase chain reaction, or the molecular-level detection of COVID-19's genetic material.
} 
has been working with McMaster Labs to conduct voluntary screenings of passengers when they arrive, then one week later, and again two weeks later to help determine if the two-week quarantine restriction is effective or could be shortened (Meaney 2020). IATA released a study in October 2020 showing that since the start of 2020, there have been 44 cases recorded of flight-related transmission of COVID-19 among 1.2 billion travelers, or one case for every 27 million travelers (IATA 2020; as noted by Meaney 2020). Such studies add to the collective body of knowledge about COVID-19 while informing governments and regulatory agencies on best practices when it comes to restrictions that are so impactful to the airline industry.

\section{Increased need for speed and flexibility in decision-making}

The impact of travel restrictions on airline operations and passenger demand is driving the need for unprecedented flexibility and speed in decision-making processes. As Buitendijk (2020) of Qatar stated, "I would say the biggest change if you talk about RM in general, is really the speed of decision-making with more uncertainty and less data." Meaney (2020) of Air Canada agreed, noting, "I think nimbleness has been highlighted as a new reality for a lot of the airlines out there; basically, to be able to react to unexpected things much more quickly."

This pressure for increased speed and flexibility in decision-making is observed across multiple functional areas, including long-term fleet planning, network planning and scheduling, crew, operations, and revenue management. Stomph (2020) of KLM explained that "network planning needs to be rethought, because if you open and close and open and close different spaces in different parts of the network continuously, you cannot make one network. You have to make a lot of networks at the same time and be able to shift quickly between them." Stomph continued, stating that today "on the network planning and scheduling side, you have to think about how you can plan for a lot of different scenarios where part of the world are open or closed, and how you deal with situations where suddenly parts of the world close up or open again... How can you make sure that once something opens up that you didn't expect, that you can fly to that market again?".

Before COVID-19, schedule reliability was 90 to $95 \%$ (Reynolds 2020). Today, "there is a lot more back and forth between revenue management and scheduling, particularly when it comes to really trying to identify where there are opportunities for demand" (Cleaz-Savoyen 2020) and to support last-minute flight cancelations (Westerhof 2020). As Ruhlin (2020) of United explained:
I think most carriers right now have a situation where for a lot of the booking curve-up until maybe a couple of months before departure-there's a lot more capacity in your schedule than you think you're likely to actually fly. It's figuring out what the demand is really going to be, keeping your schedule out there until you decide how many flights you're actually going to be able to fly, and then reducing the schedule-which, in turn, creates a new problem for revenue management that we've never dealt with in the past, where your airline has more capacity than you're actually going to fly.

Dominguez (2020) confirmed that a similar approach is being taken by Copa as they restart their international operations out of Panama:

You need to start trying to incentive demand by putting flights out, but if demand is not picking up, you need to be conservative and [cancel flights]. So, we are all making sure that we're very much in sync with revenue management, working in very tight windows to make sure that tactically we make all of the necessary compromises to put flights in production, and have gone to our crews and employees to ask for flexibility.

Thus, the need for flexibility extends to operations and crew. Sander Stomph of KLM noted that "we're moving to a world where we build 100 different schedules instead of one and make operational planning for all of them and then choose at the latest [possible time] a particular schedule to operate." More equipment swaps within an aircraft family are occurring within a 72-h window of departure to fine-tune capacity. As Meaney (2020) of Air Canada explained, the operations controller "is working with the passenger movement team as well as the maintenance the day of flight or day prior to flight to change out equipment and really fine-tune the capacity where we can to save costs. ... And I know in the last several months, we're upwards of a million dollars of fuel savings for just a day of flight and gate changes."

Multiple airlines have received concessions from their unions to assign crew to flights not a month or two weeks in advance of departure, which was common pre-COVID-19, but two to three days in advance of departure (Irrgang 2020; Rhoads 2020; Hoffman 2020). As Reynolds (2020) of Emirates explained, COVID-19 has "made a huge impact on the way we write pilot rosters. We've gotten some very flexible rosters and tripled the number of reserves we put on it because of the short notice." Similarly, Herter (2020) of IndiGo shared that they are doing "one-week to two-week rosters so that we can deal with any of the [schedule] expansion... we have so many quarantine changes, which creates demand or increases demand based on openings." 
Longer term, airlines would not expect to see crew assigned to flight within a few days of departure. However, under the current situation of volatile demand caused in large part by changing travel restrictions, many airlines are working with their crew in the cockpit and cabin to ensure they are operating flights that are generating revenue above variable operating costs.

\section{Impacts of COVID-19 on RM and a shift in RM development priorities}

Revenue management has faced multiple challenges in 2020, and many airlines have seen a shift in their development priorities. As Ruhlin (2020) of United described:

When this all started and up until today, we've seen several different phases of what we're dealing with. There was this phase in which everybody just wanted to get home from wherever they happened to be in the world, at the time that travel restrictions were announced. We moved from that into a phase in which no one wanted to fly...And then now we're in this situation, this new phase where I think everybody wants to fly again, but isn't sure when they're going to be comfortable with it. And the big problem with each of these successive phases...is that we realize for completely different reasons than the last phase that our systems just weren't built for this.

As demand plummeted at the start of the crisis, the focus of many RM departments was to "mainly keep the system up and running" and to handle the large volume of cancelations and no-shows associated with bookings that were made before the crisis (Westerhof 2020). No-show rates on day of departure "increased to levels we have never seen before" (Cleaz-Savoyen 2020) and were in excess of $90 \%$ at some airlines, including Air France-KLM (Westerhof 2020). Denied boardings during this time were "extremely low" at some airlines like United that, as Ruhlin (2020) said, was "able to work with our operations team and provide them new information that we weren't able to provide in the past about the likelihood of cancelations and the likelihood of no-shows for passengers."

At Air Canada, Richard Cleaz-Savoyen described the situation at the beginning of COVID-19 as follows:

New bookings started to collapse year-over-year, but then week-over-week and day-after-day until we reached the bottom. And on top of that, the new bookings were coming at a very, very different pace as we used to see in the past and the booking curves got very much compressed. We saw the schedule change, day after day-flights being changed, being moved, being removed. So all of our forecasting techniques that we developed over the years became incorrect and at the beginning of the pandemic, RM became manual and very much micromanaged on a day-by-day basis.

Fundamental changes in passenger demand and booking patterns have shifted development priorities within airline RM departments. Lead times for bookings have shrunk to around 10 days on average and everything is refundable (Lange 2020). Customers "want to book late, they want to have flexibility, and they expect fast refunds" (Stomph 2020). The demand mix has changed, with leisure travel and passengers "visiting friends and relatives" (VFR) becoming more prevalent than business travel. As Lange (2020) at Airbus rationalized, "I believe that we're going to get a short-term very strong hit and possibly a long-term sustained reduction in business travel...We are also starting to see a massive reduction in corporate travel spend. Many of the Fortune 500 companies are looking to reduce their travel expenditure by $50 \%$ next year. So those people who are traveling for business purposes may be traveling less often and are also unlikely to be buying high-fare packages."

Despite the shift to VFR and leisure travel, opportunities exist to offer multiple prices, as:

Some people are willing to travel and they are willing to pay for it as well. And they book in a very condensed period, and in that period, it's very important to capture the full willingness to pay of the passengers. There's still a very important role of revenue management even though it's different than it was one year ago. (Westerhof 2020)

This sentiment was echoed by Cleaz-Savoyen (2020) at Air Canada, who noted, "RM plays a significant role in achieving our objective of bringing revenue through the door and to maximize this revenue...which involves managing low demand and pockets of higher willingness-to-pay."

Belobaba (2020) at MIT expanded on how the role of RM is changing in this new environment:

Revenue management has always been traditionally one of managing demand when demand is very high and optimizing to protect seats. And if you look at [revenue management] in the traditional, segmented fare structure world, it's pretty easy to simulate and to imagine that, at $50 \%$ load factors, you're not really doing very much at all. But that's not what the world looks likes anymore. With much more prevalence of unrestricted and less restricted fare structures,...we find that it's not a case of simply opening up all of the seats...Even with low demands, you have demand that is selling down or buying down, and estimation of elasticity becomes much more important...The less restricted the fares, the more leverage there is for good 
forecasting, willing-to-pay estimation, and marginal revenue optimization.

As a result of these fundamental demand shifts, many airlines emphasized that they were viewing COVID-19 "as a catalyst for change" (Buitendijk 2020) and shifting development priorities. Air Canada, United, and Qatar all indicated a greater focus being placed on dynamic pricing and continuous pricing (Buitendijk 2020; Cleaz-Savoyen 2020; Ruhlin 2020). As Buitendijk (2020) of Qatar summed up, "The one good thing about a crisis is people now see why [dynamic or continuous pricing] is relevant and how it would complement a[n] RM system."

\section{Challenges in forecasting demand during and after COVID-19}

Forecasting demand-both during COVID-19 and after the recovery period - is another fundamental challenge that airlines are facing. According to Ruhlin (2020) of United, "The actual revenue management forecast that we relied on...has become, at least temporarily, less relevant." Stomph (2020) of KLM elaborated that "We need to reinvent the way we look at bookings or revenue management. The demand curves we used in the past [are not relevant today] and our machine learning algorithms [are not forecasting well] because the data they were trained on are no longer valid because [our historic data are] from a different era."

Traditional demand forecasting approaches are struggling to adapt to an environment that is characterized by high schedule volatility and ever-changing travel restrictions. As Lange (2020) of Airbus described, "We have no body of data, we have no body of past experience which gives us the full ability to predict what might happen." Consequently, multiple airlines have stopped using historical data to predict demand and are relying more on manual forecasts and new modeling approaches.

For example, Air Canada set up a task force to predict what the recovery profile would look like at the market level. Air Canada brought in their artificial intelligence (AI) team to forecast what the virus evolution curve could look like in the coming months and how government restrictions could impact demand. Cleaz-Savoyen (2020) explained:

We started with a very simple model based on how demand recovered from previous crises like 2008 and SARS and then progressively started adding more dimensions to it. The demand segmentation is a very important component because we're expecting the recovery profile to be very different if you are talking about VFR versus business versus leisure versus group demand.
Dennis Buitendijk at Qatar also confirmed that they are now starting to model how COVID-19 will progress, when cases will spike, and how to jointly model interactions between individuals' desire to travel and travel restrictions.

Consistent with the observation by Richard CleazSavoyen at Air Canada, Ruhlin (2020) of United noted that during COVID-19, being able to separately model leisure and business travelers instead of forecasting demand by class of service has been critical, "because it's pretty clear so far that the return to willingness to fly on the part of passengers has come a little bit earlier for leisure passengers than for business passengers." However, Ruhlin added that demand forecasting during the pandemic has been further complicated by the fact that "everything is changing so fast" and with all of the schedule volatility occurring, the ability to first forecast market-level demand and then use a passenger choice model to allocate that demand across flights is "something we really wish we had but that is hard to implement."

During this period, many airlines are relying more on revenue management users to manually adjust forecasts. As Arjan Westerhof of Air France-KLM shared, "For this moment, we believe our analysts can do a better job than the system in this area because there are a lot of variables that we don't capture in our systems, like the number of COVID19 cases, ... different travel restrictions, and schedule uncertainty." The increased reliance on manual intervention was further explained by Ruhlin at United who noted that "even as different waves of resurgence of the Coronavirus come, it's a different behavior that we're seeing among passengers and among governments and their restrictions than it was last time. So things are changing so fast that the systems are having a difficult time keeping up" (Ruhlin 2020).

As border restrictions cause pent-up demand, it has become more important for airlines to identify, uncover, and track pockets of demand so that when the travel restrictions are lifted, the airline is ready and has the right capacity to offer customers (Cleaz-Savoyen 2020). Shopping data is one source that have been used to help identify outliers that may be an indication of demand increasing (Cleaz-Savoyen 2020).

Given the shift to more manual forecasting, combined with the fact that "the data you are collecting now is not going to be helpful after the recovery" (Buitendijk 2020), many are exploring ways of blending historical data with manual overrides to support forecasting during and after the pandemic. For example, Belobaba (2020) at MIT has been looking at ways to forecast demand with no historical data and exploring ways to shorten the historical period used in forecasting, pick up on trends more quickly, and incorporate demand adjustments made by human revenue management users.

Cleaz-Savoyen (2020) described how Air Canada has been transitioning back to historical forecasts in some 
markets using a "deconfining process." They used this process initially to bring historical data back into their noshow forecasts. First, they worked with their flight model managers to establish criteria for stability and consistency. Once the forecaster was producing forecasts within the "consistent and stable" range, they would start using historical data for forecasting. The process is reviewed on a market-by-market and weekly basis. Air Canada is looking to apply a similar approach to incorporate historical information back into its demand forecaster at a future date, but noted that "it's going to require a lot more care" because demand levels and booking curves are much different now than they were pre-COVID-19 (Cleaz-Savoyen 2020). Ruhlin (2020) of United also viewed the transition to using historical data for demand forecasting to be a market-by-market decision and one in which the forecast "gets turned back on, but there's still a certain amount of overrides applied to the forecast."

\section{What lies ahead for the airline industry- new opportunities and challenges}

Many individuals within aviation are viewing 2020 as both a year of challenges and opportunities. As Lange (2020) of Airbus stated, "I strongly suspect that we will look back at 2020 as being a turning point in the history of commercial aviation or at least a point of inflection or possibly a new beginning in some way. But certainly, it's not all risk, it's risk and opportunity." Within RM, opportunities to improve demand forecasting and incorporate dynamic or continuous pricing are receiving increased attention. While booking horizons may lengthen in the post-COVID-19 period, the overall mix of passenger travel may change, with leisure and VFR trips becoming more prevalent. Post-COVID-19, passengers may demand that flexible and refundable ticketing policies continue, which will further drive the need for innovations in dynamic and continuous pricing.

The next few years for the airline industry will clearly be challenging, with demand levels not expected to return to pre-COVID-19 levels until 2023 to 2025 (Lange 2020). Regardless of what lies ahead for airlines, one message came through clearly in the keynote addresses and panels: "You shouldn't waste a good crisis—and COVID can be a real catalyst for change" (Buitendijk 2020).

Acknowledgements The authors thank all the panelists and keynote speakers who participated in the discussions, as well as Semi Gabteni, Mike Irrgang, Marcel Sol, and Daniel Stecher who helped recruit speakers and moderate the sessions. The authors are also grateful to Debbie Fleming of Administrative Plus Support Services for transcribing the panel and keynote sessions and Sharon Dunn who copy-edited the manuscript prior to submission.

\section{References}

Aznavurian, Pablo. 2020. Vice President Operations at AeroMéxico Group. Panelist in the Operations Panel: COVID-19 operations update, and when/what will be the "new normal." AGIFORS 60th Annual Symposium, October 20-23, virtual platform.

Belobaba, Peter. 2020. Director of the MIT/PODS Revenue Management Research Consortium and Professor at MIT. Panelist in the Revenue Management Panel: COVID-19: A chance to reset revenue management practices? AGIFORS 60th Annual Symposium, October 20-23, virtual platform.

Buitendijk, Dennis. 2020. Manager Operations Research at Qatar Airways. Panelist in the Revenue Management Panel: COVID-19: A chance to reset revenue management practices? AGIFORS 60th Annual Symposium, October 20-23, virtual platform.

Cleaz-Savoyen, Richard. 2020. Director, Revenue Optimization at Air Canada. Panelist in the Revenue Management Panel: COVID-19: A chance to reset revenue management practices? AGIFORS 60th Annual Symposium, October 20-23, virtual platform.

Dominguez, Bolivar. 2020. Vice President Operations at Copa Airlines. Panelist in the Operations Panel: COVID-19 operations update, and when/what will be the "new normal." AGIFORS 60th Annual Symposium, October 20-23, virtual platform.

Garrow, Laurie A. 2020a. The first 100 days: How airlines responded to the Covid-19 crisis. Avionics International, Aug/Sep. http:// interactive.aviationtoday.com/avionicsmagazine/august-septe mber-2020/the-first-100-days-how-airlines-responded-to-thecovid-19-crisis/.

Herter, Jason. 2020. Vice President OCC at IndiGo Airlines. Panelist in the Operations Panel: COVID-19 operations update, and when/ what will be the "new normal." AGIFORS 60th Annual Symposium, October 20-23, virtual platform.

Hoffman, Martin. 2020. Head of Operational Planning Optimization at SAS. Panelist in the Crew Panel: COVID-19: In search of gems amongst the lumps of coal. AGIFORS 60th Annual Symposium, October 20-23, virtual platform.

IATA. 2020. Research points to low risk for COVID-19 transmissions in flight. Press Release No. 81, October 8, IATA Pressroom. Available online at https://www.iata.org/en/pressroom/pr/202009-08-012/. Accessed November 6, 2020.

Irrgang, Mike. 2020. Vice President Commercial Logistics at Boeing. Moderator of the Operations Panel: COVID-19 operations update, and when/what will be the "new normal." AGIFORS 60th Annual Symposium, October 20-23, virtual platform.

Lange, Robert. 2020. Senior Vice President at Airbus. Keynote speaker. AGIFORS 60th Annual Symposium, October 20-23, virtual platform.

Meaney, Jeff. 2020. Director Aircraft Routing and Operations Planning at Air Canada SOC. Panelist in the Operations Panel: COVID19 operations update, and when/what will be the "new normal." AGIFORS 60th Annual Symposium, October 20-23, virtual platform.

Reynolds, Peter. 2020. Manager Network Ops Systems and Logistics at Emirates. Panelist in the Crew Panel: COVID-19: In search of gems amongst the lumps of coal. AGIFORS 60th Annual Symposium, October 20-23, virtual platform.

Rhoads, Nicolas. 2020. Senior Vice President Labour Strategy and Crew Planning at AeroMéxico. Panelist in the Crew Panel: COVID-19: In search of gems amongst the lumps of coal. AGIFORS 60th Annual Symposium, October 20-23, virtual platform.

Ruhlin, Eric. 2020. Managing Director Revenue Decision Support at United Airlines. Panelist in the Revenue Management Panel: COVID-19: A chance to reset revenue management practices? AGIFORS 60th Annual Symposium, October 20-23, virtual platform. 
Stomph, Sander. 2020. Vice President at KLM Royal Dutch Airlines. Keynote speaker. AGIFORS 60th Annual Symposium, October 20-23, virtual platform.

Westerhof, Arjan. 2020. Manager Revenue Management Systems at Air France-KLM. Panelist in the Revenue Management Panel: COVID-19: A chance to reset revenue management practices? AGIFORS 60th Annual Symposium, October 20-23, virtual platform.

Publisher's Note Springer Nature remains neutral with regard to jurisdictional claims in published maps and institutional affiliations.

Laurie Garrow is a Professor of Civil and Environmental Engineering and Co-Director of the Center for Urban and Regional Air Mobility at the Georgia Institute of Technology. She currently serves as President of AGIFORS. Her areas of research expertise include air travel demand, discrete choice modeling, urban air mobility, and revenue management.

Virginie Lurkin is an Assistant Professor in the Department of Industrial Engineering \& Innovation Sciences at Eindhoven University of Technology. She currently serves as Co-Chair of the Revenue Management Study Group of AGIFORS. Her research interests are in choice modeling and optimization; the domain of application of her work is the transportation industry. 